\title{
Compliance with nasal CPAP therapy for obstructive sleep apnoea: how much is enough?
}

\author{
W.T. McNicholas
}

Nasal continuous positive airway pressure (NCPAP) is a highly effective therapy for obstructive sleep apnoea (OSA), and can completely abolish apnoeas when effective pressure levels are used during sleep [1]. However, the device is cumbersome, and several studies have demonstrated only moderate compliance, with reports indicating 3-6 h use on an average nightly basis [2-4]. This observation indicates that patients spend considerable parts of the night without effective therapy, and raises the question of what happens to the patients' OSA during the sleep period without effective therapy. Since the severe end of the OSA spectrum is typically characterized by apnoea and hypopnoea frequencies in excess of 50 events $\cdot h^{-1}$, and associated with episodic profound hypoxaemia, even a few hours without effective therapy could be associated with several hundred apnoeas and/or hypopnoeas, with consequent episodic severe hypoxaemia.

There is considerable evidence that OSA carries a substantial morbidity and mortality, particularly from cardiovascular complications [5-8]. Whilst there is evidence that NCPAP reduces mortality [9], the literature is limited on the long-term outcome of OSA, both treated and untreated. Major concern persists about the possible adverse health effects of leaving OSA patients without effective therapy for up to half of each night. However, several studies have demonstrated that, in clinical practice, NCPAP dramatically reduces the daytime sleepiness which is a typical feature of OSA, both in patients and their bed partners [10, 11]. Clear-cut objective benefits in terms of reduced daytime sleepiness and improved cognitive function have been demonstrated from average nightly treatment durations of only $3 \mathrm{~h} \mathrm{[12].} \mathrm{These} \mathrm{findings} \mathrm{indicate} \mathrm{that} \mathrm{either} \mathrm{the}$ limited period of normal sleep while on NCPAP is sufficient to produce these benefits, or that there is a benefit from NCPAP that persists into the latter part of the night, even though the device might not be in use.

The paper by Hers et al. [13] in this issue of the Journal provides important information on what happens to OSA in that part of the night without effective NCPAP therapy, and demonstrates a clinically important residual benefit which persists in the latter part of the night after NCPAP withdrawal. The frequency of apnoeas and hypopnoeas was almost halved, and the severity of oxygen desaturations greatly reduced, when compared with the latter part of a previous study night without NCPAP therapy. Furthermore, movement arousals were

Dept of Respiratory Medicine and the Respiratory Sleep Laboratory, St. Vincent's Hospital, Elm Park, Dublin 4, Ireland. fewer, despite the fact that sleep stages were similar between the two study periods of therapy. These findings provide reassurance to clinicians who may be concerned about the possible adverse health effects of limited compliance with NCPAP in many of their OSA patients. Nevertheless, the authors are careful to draw attention to other reports that have failed to demonstrate a significant residual benefit after acute NCPAP withdrawal. Most of these reports, however, have examined the effects of withdrawal for at least one full night.

The mechanisms of this residual effect are not clear, since NCPAP appears to act as a simple positive pressure splint to counteract the upper airway collapse caused by negative suction pressure during inspiration [14], and one might, therefore, expect OSA to return to its previous severity immediately following withdrawal of therapy. Recent evidence from our department suggests that reflex mechanisms may also be involved in the action of NCPAP [15], although, again, this finding would not necessarily suggest a residual beneficial effect after NCPAP withdrawal.

It is recognized that the duration of apnoeas increases as the night progresses [16], and it could be argued, as the authors themselves point out, that the period off NCPAP resembles the early part of a night's sleep without therapy, and this might account for at least part of the improvement observed. Other factors, such as improved sleep quality with fewer movement arousals in addition to improved gas exchange while on NCPAP, may also contribute to this residual beneficial effect. Nasal CPAP therapy in OSA has been shown to be associated with a variety of potentially beneficial neuromuscular and mechanical changes affecting the upper airway, including: reduced pharyngeal oedema; increased upper airway cross-sectional area; reduced upper airway collapsibility; and improved ventilatory load compensation [17-20]. Whilst the data available do not indicate that these effects might occur after only a few hours of therapy, as in the study by HeRs et al. [13] long-term therapy with NCPAP could well produce mechanical benefits to the upper airway that would persist for at least several hours after NCPAP withdrawal, and thus produce a persisting benefit for the latter part of the night among the majority of patients who only use their device for the early part of each night.

The fact that patients use their NCPAP device for only part of the night raises the possible benefit of adding other modalities of therapy, together with NCPAP, in patients with moderate-to-severe OSA. Prior to the widespread use of NCPAP, there was considerable interest 
in pharmacological therapy, and a number of agents have been shown to have limited beneficial effects in this disorder [21-23]. Pharmacological therapy fell out of favour, to a large extent, once the use of NCPAP became widespread, because of the realization that NCPAP was a much more effective form of therapy. However, if patients spend on average $30-50 \%$ of each night without NCPAP, the addition of one or more pharmacological agents might provide some additional benefit during this latter part of the night. Further study will be required to establish whether such additional therapy provides significant clinical benefit. The limited compliance with NCPAP should also be taken into account when comparing the relative efficacy of NCPAP with other forms of therapy that might be somewhat less effective but better tolerated, such as oral prostheses.

Nasal CPAP is now established as the preferred treatment option for moderate and severe OSA, and those who treat such patients have no doubt about its efficacy. However, there is a shortage of controlled trials that have examined the clinical outcome of NCPAP, particularly in the medium- to long-term setting. Whilst it would be hard to ethically justify placebo-controlled trials in severe cases of OSA, such trials in mild-tomoderate disease are both appropriate and necessary. Given the very common nature of the disorder [24, 25 ], it is important that clear-cut objective evidence be obtained both of the natural history of the disorder, and the impact of treatment with NCPAP. The European Respiratory Society Task Force on "Public Health and Medicolegal Implications of Sleep Apnoea" is presently planning a large scale multicentre trial of NCPAP along these lines, which will hopefully confirm the benefits observed in clinical practice.

\section{References}

1. Sullivan CE, Issa FG, Berthon-Jones M, Eves L. Reversal of obstructive sleep apnoea by continuous positive airway pressure applied through the nares. Lancet 1981: i: 862-865.

2. Krieger J, Kurtz D. Objective measurement of compliance with nasal CPAP treatment for obstructive sleep apnoea syndrome. Eur Respir J 1988; 1: 436-438.

3. Rauscher H, Formanek D, Popp W, Zwick H. Selfreported $v s$ measured compliance with nasal CPAP for obstructive sleep apnea. Chest 1993; 103: 1675-1680.

4. Reeves-Hoche MK, Meck R, Zwillich CW. Nasal CPAP: an objective evaluation of patient compliance. Am J Respir Crit Care Med 1994; 149: 149-154.

5. Partinen M, Guilleminault C. Daytime sleepiness and vascular morbidity at seven year follow-up in obstructive sleep apnea patients. Chest 1990: 97: 27-32.

6. Hung J, Whitford EG, Parsons RW, Hillman DR. Association of sleep apnoea with myocardial infarction in men. Lancet 1990; 336: 261-264.

7. Hoffstein V. Blood pressure, snoring, obesity, and nocturnal hypoxaemia. Lancet 1994; 344: 643-645.

8. Partinen M, Jamieson A, Guilleminault C. Long-term outcome for obstructive sleep apnea patients. Chest 1989; 94: 1200-1204.
9. He J, Kryger MH, Zorick FJ, Conway YW, Roth T. Mortality and apnea index in obstructive sleep apnea: experience in 385 male patients. Chest 1988: 94: 9-14.

10. Hardinge FM, Pitson DJ, Stradling JR. Use of the Epworth Sleepiness Scale to demonstrate response to treatment with nasal continuous positive airways pressure in patients with obstructive sleep apnoea. Respir Med 1995; 89: 617-620.

11. Kiely JL, McNicholas WT. Response of patients and bed partners to nasal continuous positive airway pressure for obstructive sleep apnoea. Eur Respir J 1996; 9 (Suppl. 23): 463s.

12. Engleman HM, Martin SE, Deary IJ, Douglas NJ. Effect of continuous positive airway pressure treatment on daytime function in sleep apnoea/hypopnoea syndrome. Lancet 1994; 343: 572-575.

13. Hers V, Liistro G, Dury M, Collard Ph, Aubert G, Rodenstein DO. Residual effect of nCPAP applied for part of the night in patients with obstructive sleep apnoea. Eur Respir J 1997; 10: 973-976.

14. Remmers JE, DeGroot WJ, Sauerland EK, Anch AM. Pathogenesis of upper airway occlusion during sleep. $J$ Appl Physiol: Respirat Environ Exercise Physiol 1978; 44: 931-938.

15. Deegan PC, Nolan P, Carey M, McNicholas WT. Effects of positive airway pressure on upper airway dilator muscle activity and ventilatory timing. J Appl Physiol 1996; 81: 470-479.

16. Charbonneau M, Marin JM, Olha A, Kimoff J, Levy $\mathrm{RD}$, Cosio MG. Changes in obstructive sleep apnea characteristics through the night. Chest 1994; 106: 1695-1701.

17. Abbey NC, Block AJ, Green D, Mancuso A, Hellard DW. Measurement of pharyngeal volume by digitized magnetic resonance imaging: effect of nasal continuous positive airway pressure. Am Rev Respir Dis 1989; 140: 717-723.

18. Strohl KP, Redline S. Nasal CPAP therapy, upper airway muscle activation, and obstructive sleep apnea. Am Rev Respir Dis 1986; 134: 555-558.

19. Mortimore IL, Kochhar P, Douglas NJ. Effect of chronic continuous positive airway pressure (CPAP) therapy on upper airway size in patients with sleep apnoea/hypopnea syndrome. Thorax 1996; 51: 190-192.

20. Greenberg HE, Scharf S. Depressed ventilatory load compensation in sleep apnea: reversal by nasal CPAP. Am Rev Respir Dis 1993; 148: 1610-1615.

21. Mulloy E, McNicholas WT. Theophylline in obstructive sleep apnea: a double-blind evaluation. Chest 1992; 101: 753-757.

22. Rajagopal KR, Albrecht PH, Jabbari B. Effects of medroxy-progesterone acetate in obstructive sleep apnea. Chest 1986; 90: 815-821.

23. Brownell LG, West P, Sweatman P, Acres JC, Kryger $\mathrm{MH}$. Protriptyline in obstructive sleep apnea; a doubleblind trial. N Engl J Med 1982; 307: 1037-1042.

24. Stradling JR, Crosby JH. Predictors and prevalence of obstructive sleep apnoea and snoring in 1,001 middleaged men. Thorax 1991; 46: 85-90.

25. Young T, Palta M, Dempsey J, Skatrud J, Weber S, Badr S. The occurrence of sleep-disordered breathing among middle-aged adults. $N$ Engl J Med 1993; 328: 1230-1235. 